\title{
Effects of stretching stress on the muscle contraction proteins of skeletal muscle myoblasts
}

\author{
Koji SakiYama ${ }^{1}$, Shinichi Abe ${ }^{1,2}$, Yuichi Tamatsu ${ }^{3}$ and Yoshinobu $\operatorname{IdE}^{1}$ \\ ${ }^{1}$ Department of Anatomy, ${ }^{2}$ Oral Health Science Center and Department of Anatomy, Tokyo Dental College, and ${ }^{3}$ Department of Neu- \\ rology Gross Anatomy Section, Kagoshima University Graduate School of Medical and Dental Sciences
}

(Received 29 December 2004; and accepted 26 January 2005)

\begin{abstract}
Several studies have reported that growth and differentiation of cultured myoblasts can be facilitated by applying appropriate mechanical stimulus. However, the effects of mechanical stimulus on the characteristics of muscle fibers have not yet been fully elucidated. In this study, we gave mechanical stress to $\mathrm{C} 2 \mathrm{C} 12$ cells, which were myoblasts derived from mice skeletal muscle. The following myosin heavy chain (MHC) isoforms were investigated in order to clarify muscle characteristics: MHC-2b, 2d and 2a, all of which are fast-twitch fibers. After inoculating cells on a silicone chamber, the chamber was mechanically stretched, and a LightCycler ${ }^{\mathrm{TM}}$ was used to measure the mRNA expression of each MHC isoform at several times. The results showed that, with mechanical stretching, the expression of MHC-2b was initially high. On the other hand, without stretching, the expression of MHC-2d increased over time, but with stretching, it was hardly seen. Furthermore, the expression of MHC-2a was significantly high in the stretching group. These results of this study suggest that, when intermittently stimulated, myoblasts express increased levels of MHC-2a isoform. Therefore, it is indicated that myocytes respond to environmental changes not only to facilitate growth and differentiation, but also to alter muscle function actively at the $\mathrm{MHC}$ isoform level.
\end{abstract}

Myosin heavy chain (MHC), which is a muscle contraction protein, is known to be closely related to muscle function (14). Also, MHC consists of several isoforms, and changes in muscle function can be determined by the composition ratios of these isoforms $(2,14)$. In adult mice, there are four MHC isoforms; MHC-2b, 2d, 2a and 1, and in vivo studies have shown that these isoforms may undergo the following reversible changes: $2 \mathrm{~b} \rightleftarrows 2 \mathrm{~d} \rightleftarrows 2 \mathrm{a} \rightleftarrows 1$ (15). MHC-2b, 2d and $2 \mathrm{a}$ are all fast-twitch fibers, and the contraction speed for MHC-2b is the fastest, followed by $2 \mathrm{~d}$ and $2 \mathrm{a}$, and MHC-1 is slow-twitch fi-

Address correspondence to: Dr. Koji Sakiyama, Department of Anatomy, Tokyo Dental College, 1-2-2 Masago, Mihama-ku, Chiba 261-8502, Japan

Tel: +81-43-270-3571, Fax: +81-43-277-4010

E-mail: sakiyama@tdc.ac.jp ber (1).

As to the relationship between the composition ratios of MHC isoforms and changes in muscle function, one study investigated the masseter muscle in fetal and newborn mice (19). The results showed that the composition ratios of MHC isoforms changed markedly at 16 days post conception when many oral tissues became ready for delivery and slight jaw movements began. Another study investigated the development process for the mouse masseter muscle after birth, and reported that the composition ratios of MHC isoforms changed markedly during weaning when the masseter muscle began to masticate instead of suckle $(6,17)$. These two investigations suggested a possibility that changes in muscle function leads to changes in MHC isoform composition. However, it is also possible that changes in $\mathrm{MHC}$ isoform are related to 
genetic regulations but not to environmental changes. Recently, there have been more reports on changes in muscle function and MHC isoforms during the growth phase. In some of these studies, the effects of mechanical stimuli on the growth and development of cultured myoblasts have been assessed $(3,20)$. Then, it has become clear that when appropriate mechanical stimuli are applied, growth and development of cultured cells can be promoted, and cell arrangement as well as cytoskeleton are affected $(3,5,21)$. In this experiment system, it is possible to determine the effects of a stimulus on the characteristics of muscle fibers by measuring the composition of isoforms during the growth phase. However, no studies have yet measured mRNA expression in MHC isoforms. In the present study, cultured myoblasts were mechanically stretched in order to evaluate the effects of this mechanical stimulation on the characteristics of muscle fibers, including mRNA expression in fast-twitch MHC isoforms (MHC-2b, $2 \mathrm{~d}$ and $2 \mathrm{a}$ ).

\section{MATERIALS AND METHODS}

Cell culture. $\mathrm{C} 2 \mathrm{C} 12$ cells, which are mice skeletal muscle myoblasts, were used in this study. $\mathrm{C} 2 \mathrm{C} 12$ cells are an established cell line originating from mice skeletal muscle, and as a result, subculturing is possible and proliferation is stable (22). It has also been reported that differentiation of $\mathrm{C} 2 \mathrm{C} 12$ cells can be induced using media with relatively low serum concentrations, such as serum-free media or media containing $2 \%$ horse serum (7). Cells were maintained in Dulbecco's modified Eagle's medium (DMEM) (Sigma-Aldrich Co., St. Louis, MO) containing Penicilin-Streptomycin Solution (Sigma Aldrich Co.) and $2 \%$ or $10 \%$ fetal bovine serum (FBS) (ICN Biomedicals Inc., Aurora, OH) was used. We used stretching medium containing 2\% FBS. Myoblasts were cultured at $37^{\circ} \mathrm{C}$ under $5 \%$ carbon dioxide. $\mathrm{C} 2 \mathrm{C} 12$ cells $\left(2.5 \times 10^{5}\right.$ cells/well $)$ were cultured using type 1 collagen-coated 6-well BioFlex ${ }^{\circledR}$ culture plates (well diameter: $25 \mathrm{~mm}$ ) (Flexcell International Corp., Mckeesport, PA). In order to attach these cells to the plates, cells were cultured using $2.0 \mathrm{ml}$ DMEM containing 10\% FBS for half a day. After $12 \mathrm{~h}$, DMEM containing 2\% FBS was used, and the resulting cultured cells were mechanically stretched. The following three observation stages were established: Stage I (one day after the start of culturing, or $12 \mathrm{~h}$ after the start of stretching), Stage II (two days after Stage I) and Stage III (two days after Stage II). The culture solution was exchanged everyday.

Mechanical stretching, and how to count the number of cells and nuclei. Mechanical stretching was conducted using a Flexercell ${ }^{\circledR}$ strain unit (Flexcell International Corp.). $\mathrm{C} 2 \mathrm{C} 12$ cells were stretched by a vacuum created under the membrane using a pump (Fig. 1). The intensity of stretching was $15 \%$ at the maximally stretched area, and in this stretching stimulation, the membrane was stretched for $1 \mathrm{~s}$ and then relaxed for $1 \mathrm{~s}$. This intermittently stimulation was repeated.

Morphological characteristics of cultured cells at each stage were observed using a phase-contrast microscope (Nikon, Tokyo, Japan).

At each stage, cultured cells were immersed in trypsin-EDTA (Gibco BRL, Gland Island, NY) for $5 \mathrm{~min}$. After detaching the cells, they were thoroughly soaked in culture solution, and the number of cells was counted using a hemocytometer. Fused cells were counted as one. To ascertain the effects of stretching on cell fusion, the number of nuclei was counted in multinucleated muscle fibers. Detached cultured cells were stained using Nuclear Fast Red (Funakoshi, Tokyo, Japan), washed using phosphate buffered saline (PBS), and then counted using a hemocytometer. We counted the number of cells and nuclei eight times.

$m R N A$ expression analyses. In order to investigate the effects of mechanical stretching at the mRNA

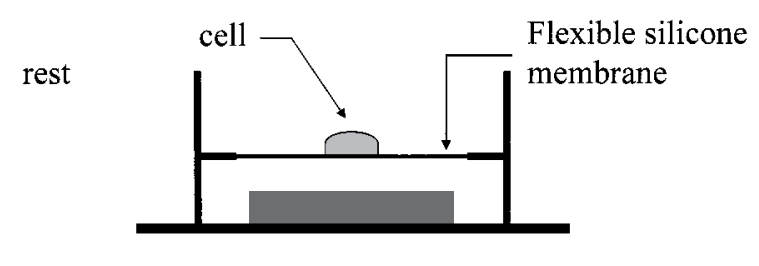

stretch

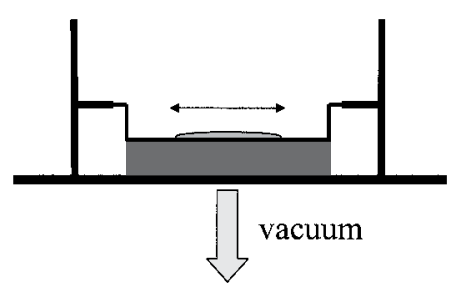

Fig. 1 Schematic diagram of stretching. By creating a vacuum under the chamber, the membrane that the cultured cells were placed on was pulled downward, thus stretching the cultured cells. 
level, the LightCycler ${ }^{\mathrm{TM}}$ instrument (Roche Molecular Biochemicals, Mannheim, Germany) was used to quantify mRNA expression in each MHC isoform at each stage: after extracting mRNA using a QuickPrep micro mRNA Purification Kit (Amersham Pharmacia Biotech UK Ltd., Buckinghamshire, UK), cDNA was prepared using Ready-To-Go PCR T-Printed First Standard kit (Amersham Pharmacia Biotech UK Ltd.). After establishing the optimal conditions for all primers, mRNA expression was quantified according to the standard LightCycler ${ }^{\mathrm{TM}}$ protocol. As a hot start PCR solution for the LightCycler $^{\mathrm{TM}}$, adjusted LC FastStart DNA Master SYBR Green I (Roche Molecular Biochemicals) was used. In the PCR mixture for demonstration runs for each diluted PCR product, to $10.2 \mu \mathrm{l}$ of sterile water, $2 \mu 1$ of LC FastStart DNA Master SYBR Green I containing $\lambda$ DNA $(5 \mathrm{pg} / \mu \mathrm{l})$ and SYBR Green $1(1 / 60,000$ dilution), and $1.6 \mu \mathrm{l}$ of $\mathrm{MgCl}_{2}(25 \mathrm{mM})$ were added. Furthermore, after adding $0.6 \mu \mathrm{l}$ each of a sense primer $(10 \mathrm{pmol} / \mu \mathrm{l})$ and an antisense primer $(10$ $\mathrm{mol} / \mu \mathrm{l})$ prepared using Oligo 5 primer design (Biogene, Ltd., Kimbolton, UK), $5 \mu 1$ of each diluted PCR product was added, bringing the final reaction volume to $20 \mu \mathrm{l}$. The primers for MHC-2b, $2 \mathrm{~d}$ and $2 \mathrm{a}$ were designed by selecting a unique sequence from the full DNA sequence of each isoform. The base sequence of the primers for each isoform was follows: MHC-2b (sense primer: 5'-ACAGACTA AAGTGAAAGCC-3', antisense primer: 5' -CTCT CAACAGAAAGATGGAT-3', Accession: XM 126119); MHC-2d (sense primer: 5'-GGACAAACT GCAATCAAAGG-3', antisense primer: 5-TTGGT CACTTTCCTGCACTT-3', Accession: AJ293626); and MHC-2a (sense primer: 5'-CGATGATCTTGC CAGTAATG-3, antisense primer: 5'-TGATAACT GAGATACCAGCG-3', Accession: NM_144961). With regard to the PCR mixture, to $14.2 \mu \bar{l}$ of sterile water, $2 \mu 1$ of LC FastStart DNA Master SYBR Green I containing $\lambda$ DNA $(5 \mathrm{pg} / \mu \mathrm{l})$ and SYBR Green 1 (1/60,000 dilution), $1.6 \mu 1$ of $\mathrm{MgCl}_{2}$ $(25 \mathrm{mM})$, and $0.6 \mu \mathrm{l}$ each of a forward primer $(10 \mathrm{pmol} / \mu \mathrm{l})$ and a reverse primer $(10 \mathrm{pmol} / \mu \mathrm{l})$ were added. In addition, $1 \mu \mathrm{l}$ of target DNA was added to bring the final reaction volume to $20 \mu$ l. Each PCR mixture $(20 \mu \mathrm{l})$ prepared in the above manner was added to the glass section of each capillary. PCR was performed at $95^{\circ} \mathrm{C}$ for $10 \mathrm{~min}$ and then at $95^{\circ} \mathrm{C}$ for $10 \mathrm{~s}, 62^{\circ} \mathrm{C}$ for $10 \mathrm{~s}$ and $72^{\circ} \mathrm{C}$ for $7 \mathrm{~s}$ for a total of 50 cycles. As to gene amplification, according to a melting program of $70^{\circ} \mathrm{C}$ for $15 \mathrm{~s}$, fluorescence was continuously monitored at a rate of $0.1^{\circ} \mathrm{C}$ per second during the transition phase from 70 to $95^{\circ} \mathrm{C}$.
F1 $(530 \mathrm{~nm})$ was used as a fluorescent channel, and the gain indicated $88.8^{\circ} \mathrm{C}$ for MHC-2b, $89.0^{\circ} \mathrm{C}$ for MHC-2d and $88.6^{\circ} \mathrm{C}$ for MHC-2a. The amount of each MHC isoform calculated by the above-mentioned methods was divided by the amount of $\beta$-actin, which was one of house keeping genes, to determine the mRNA expression of each isoform. The base sequence of $\beta$-actin was as follows: (sense primer: 5'-CCTGTATGCCTCTGGTCGTA-3', antisense primer: 5'-CCATCTCCTGCTCGAAGTCT-3', Accession: X-03672). Each PCR fragment was verified as part of an MHC isoform by ABI PRISM 310 Genetic Analyzer (Perkin-Elmer Japan Applied Biosystem, Tokyo, Japan).

\section{RESULTS}

Effects of stretching on the morphological characteristics of cultured cells (Fig. 2)

In stage I, no difference was noted between the control and stretch groups. In stage II, the number of cells increased in the stretch group. At Stage III, the cells in the control group (without mechanical stretching) were arranged irregularly, but those in the stretching group were arranged with some directionality. In addition, there were numerous long narrow cells that fused.

Effects of stretching on the numbers of cells (Fig. 3) and nuclei (Fig. 4)

In the control group, the number of cells increased at a constant rate from Stages I to III. On the other hand, in the stretch group, the number of cells increased rapidly between Stages I and II, but remained mostly unchanged between Stages II and III. The number of nuclei also increased at a constant rate from Stages I to III in both groups, but the number of nuclei in the stretch group was significantly higher than that in the control group in Stages II and III. This demonstrates that the application of stretch stimuli promoted cell fusion. Next, to investigate the relationship between the amount of load on muscle fibers and the change in the properties of muscle fibers, we determined the level of each isoform component.

mRNA expression using a LightCycler ${ }^{T M}$

Observed single band indicates that each primer was specific to each MHC type (Fig. 5). In addition, we confirmed that these reaction were only one in melting curve (Figs. 6, 7, 8). For both stretch and control groups, mRNA expression in all isoforms was confirmed at each stage. In the stretch group, the 

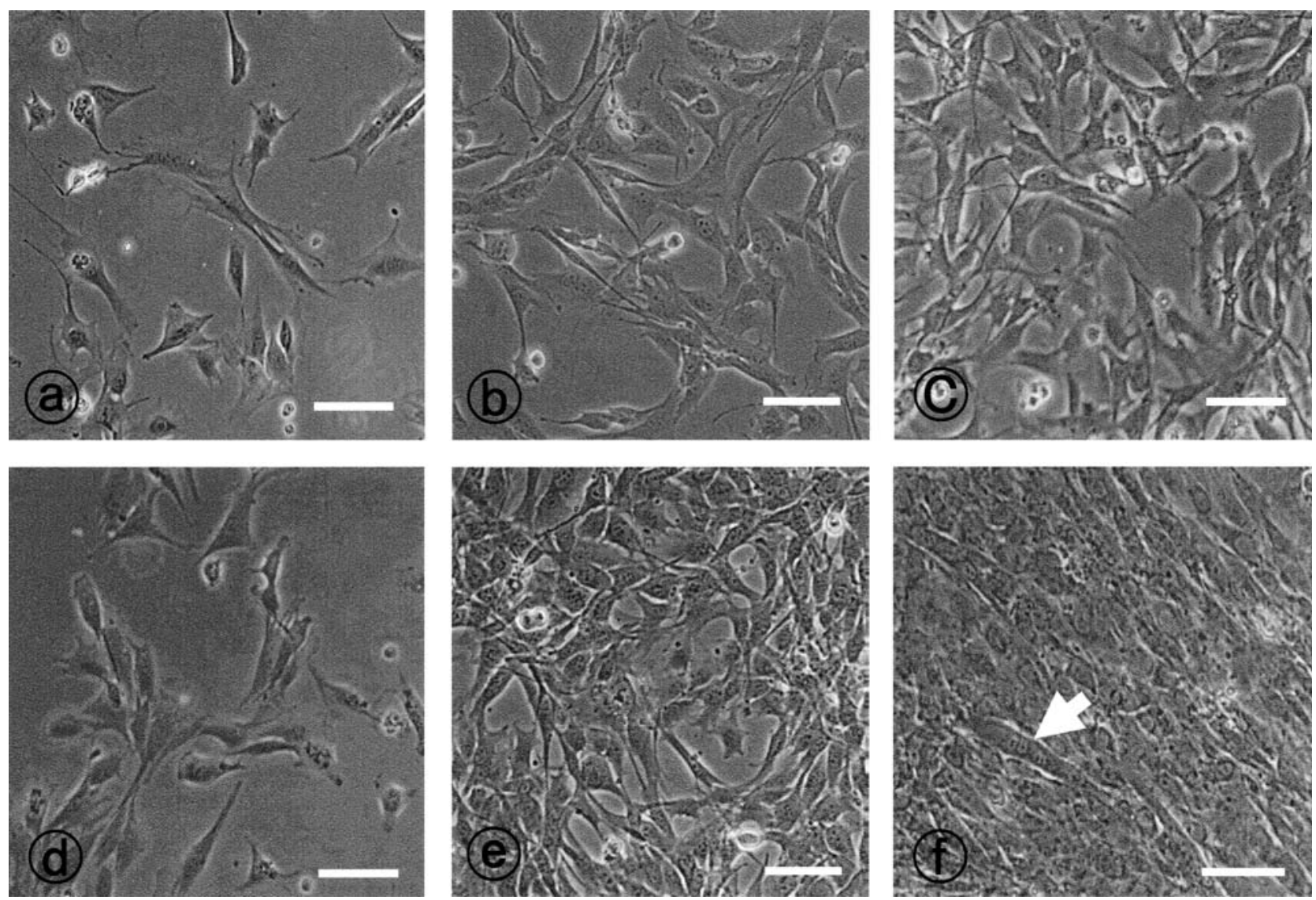

Fig. 2 A phase contrast microscope image of myoblasts at each stage.

a-c: control group. d-f: stretch group. a, d: stage I. b, e: stage II. c, f: stage III. An arrow in f shows a long, slender multinucleus cell. Bars: $100 \mu \mathrm{m}$

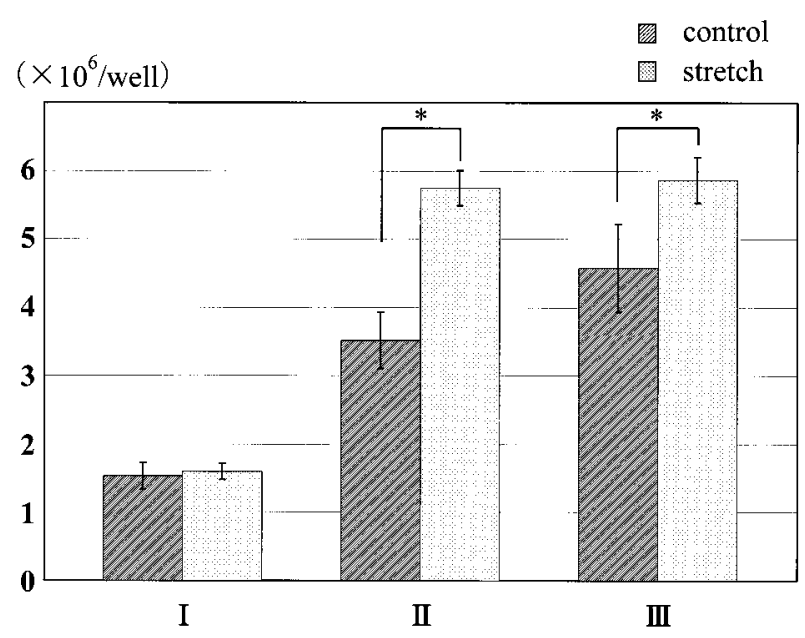

Fig. 3 Number of myoblasts at each stage. (mean \pm S.D.) Statistical analysis: ${ }^{*} p<0.005(n=10)$.

mRNA expression of MHC-2b (fastest contraction speed) was highest at stage I. However, its expres-
$\left(\times 10^{6} /\right.$ well $)$
圆 control
圈 stretch

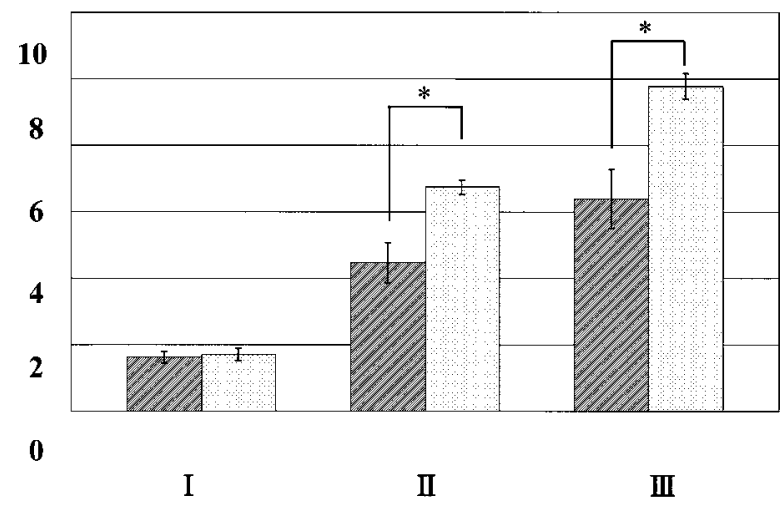

Fig. 4 Number of myoblast nuclei at each stage. (mean \pm S.D.) Statistical analysis: ${ }^{*} p<0.005(n=10)$.

sion decreased rapidly at stage II, and then hardly changed at stage III. On the other hand, in the con- 


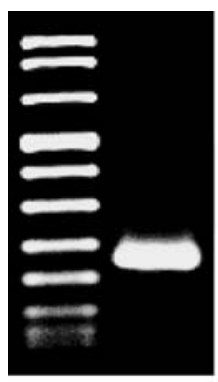

MHC-2b

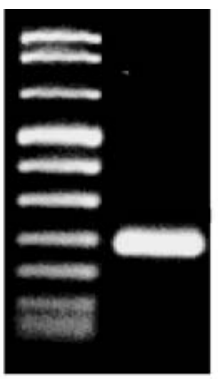

MHC-2d

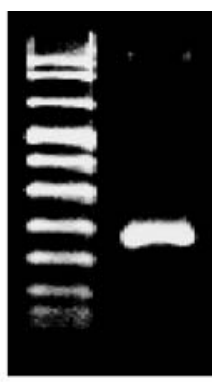

MHC-2a
Fig. 5 RT-PCR

The numbers of base pairs in primer were 215, 232 and 223. Observed single band indicates that each primer was specific to each MHC type.

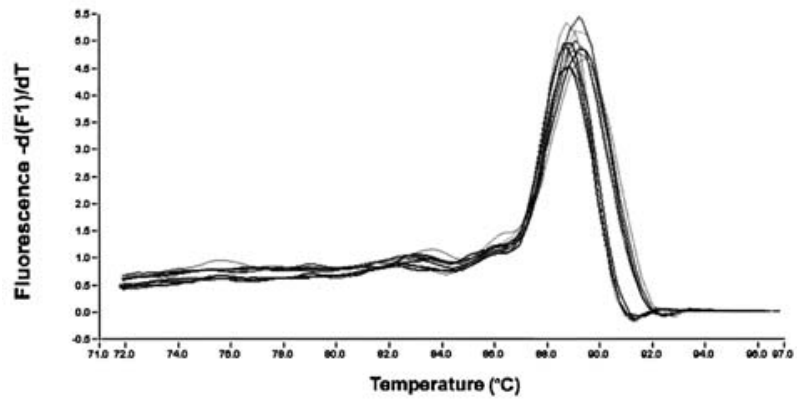

Fig. 7 Melting curve of $\mathrm{MHC}-2 \mathrm{~d}$

F1 (530 nm) was used as a fluorescent channel. The gain indicated $89.0^{\circ} \mathrm{C}$ for $\mathrm{MHC}-2 \mathrm{~d}$.

trol group, only a few mRNA expressions of MHC$2 \mathrm{~b}$ were detected at all stages (Fig. 9).

The mRNA expression of MHC-2d (intermediate isoform) in the control group was significantly higher than that in the stretch group at Stages II and III. In the control group, the mRNA expression of MHC-2d increased rapidly at Stage II and was even higher at Stage III (Fig. 10).

In both stretch and control groups, mRNA expression in MHC-2a (slowest contraction speed) increased at Stage II. However, mRNA expression in MHC-2a at Stage III decreased in the control group, but increased in the stretch group (Fig. 11).

\section{DISCUSSION}

Effects of mechanical stretching on cultured cells

Numerous reports have been published on the relationship between mechanical stimuli and the growth of various cultured cells. One study stretched cultured chicken myoblasts and documented that the number of total nuclei was higher than when these

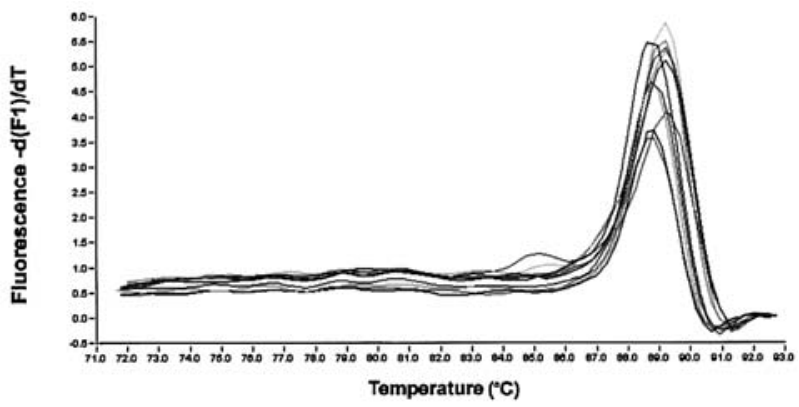

Fig. 6 Melting curve of MHC-2b

F1 $(530 \mathrm{~nm})$ was used as a fluorescent channel. The gain indicated $88.8^{\circ} \mathrm{C}$ for MHC-2b.

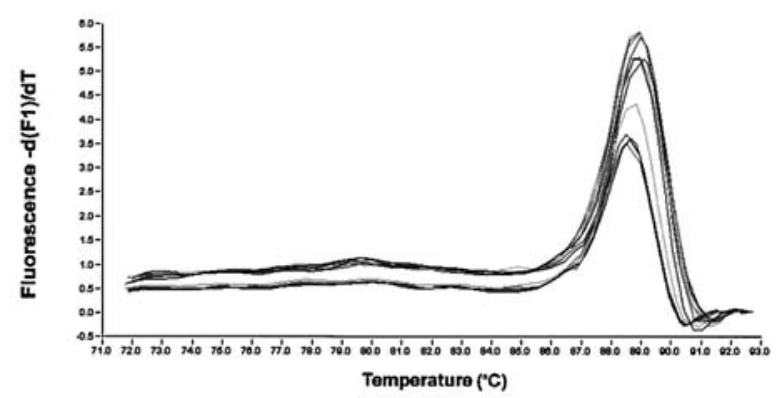

Fig. 8 Melting curve of MHC-2a

$\mathrm{F} 1(530 \mathrm{~nm})$ was used as a fluorescent channel. The gain indicated $88.6^{\circ} \mathrm{C}$ for $\mathrm{MHC}-2 \mathrm{a}$.

cells were not stretched. It was concluded that stretching facilitated fusion of myoblasts and became to multinucleated myotubes (21). Other studies confirmed the effects of stretching on the cytoskeleton: When cultured myoblasts were stretched repeatedly, actin in cytoskeleton aligned perpendicular to the direction of stretching $(3,5)$. The reason for this phenomenon may be that the actin realigned in order to improve resistance to the stretching.

The stretch-activated (SA) channel is one of the cellular membrane channels that responds to external mechanical stresses, and when the membrane stretches, this channel is activated, allowing a large quantity of $\mathrm{Ca}^{2+}$ into the cell (8). $\mathrm{Ca}^{2+}$ also plays an important role in muscle regeneration (13). $\mathrm{Ca}^{2+}$ inflow activates calcineurin, which is a $\mathrm{Ca}^{2+} /$ calmodulin dependent phosphatase, and when a transcription factor, NF-AT1, is transported into the nucleus, muscular hypertrophy is induced (16).

In one study, when a surgically-removed and cultured human anterior cruciate ligament was mechanically stretched, the amounts of collagen I and III 


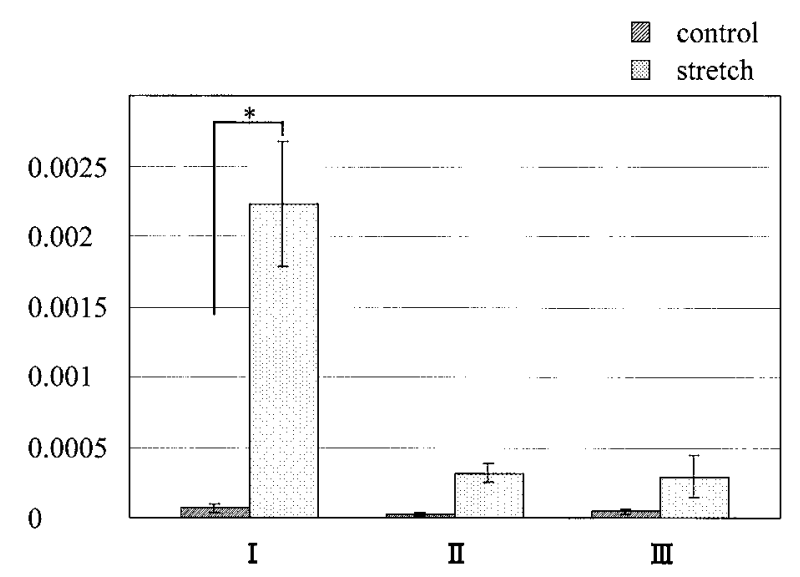

Fig. 9 mRNA expression of MHC-2b

The amount of MHC-2b calculated by the described in the text was divided by the amount of $\beta$-actin, which was one of house keeping genes, to determine the mRNA expression. (mean \pm S.D.) Statistical analysis: ${ }^{*} p<0.005(n=8)$.

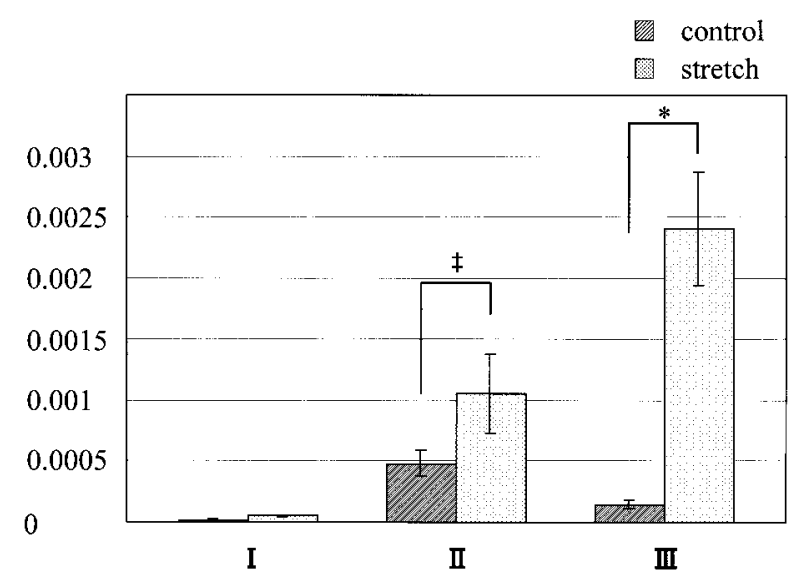

Fig. 11 mRNA expression of $\mathrm{MHC}-2 \mathrm{a}$

The amount of MHC-2a calculated by the described in the text was divided by the amount of $\beta$-actin, which was one of house keeping genes, to determine the mRNA expression. (mean \pm S.D.) Statistical analysis: ${ }^{*} p<0.005$. ${ }^{\ddagger} p<0.05$ $(n=8)$.

increased. Because the amount of collagens I and III are reduced by suppressing TGF- $\beta 1$ released by ligament cells, TGF- $\beta 1$ is involved in ligament regeneration. As a result, when ligament cells were stretched, levels of TGF- $\beta 1$ released by the cells also increased in order to activate the regeneration of ligament cells (9). In this way, numerous studies have found that mechanical stretching affects cellular growth.

The present study also showed that the number of cells and nuclei in the stretch group were significantly higher than those in the control group. In ad-

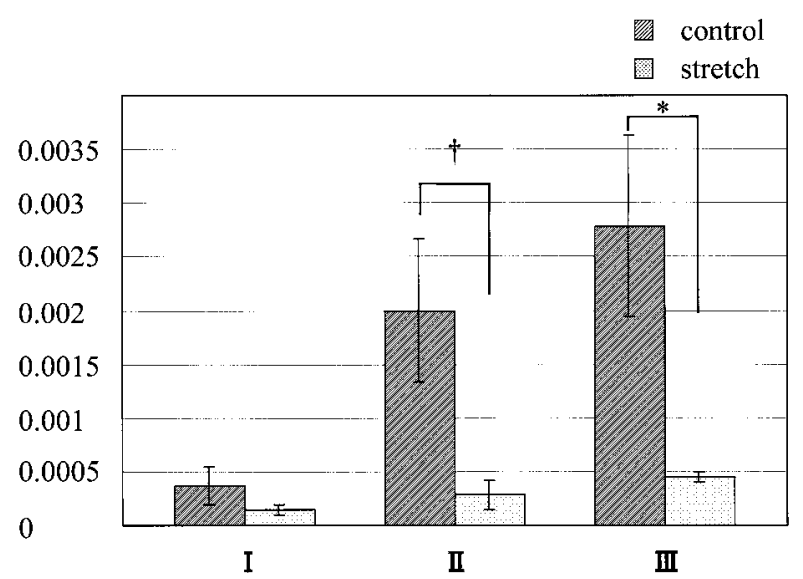

Fig. 10 mRNA expression of MHC-2d

The amount of MHC-2d calculated by the described in the text was divided by the amount of $\beta$-actin, which was one of house keeping genes, to determine the mRNA expression. (mean \pm S.D.) Statistical analysis: ${ }^{*} p<0.005 .{ }^{\dagger} p<0.01$ $(n=8)$.

dition, multinucleated myotube like cells were observed at stage III in the stretch group. These results suggest that direct stimuli to cultured myoblasts accelerate not only increase of cells (cellular growth) but also cell fusion.

Changes in the composition of each MHC isoform in mechanically-stretched cultured cells

In the stretch group MHC-2b greatly increased immediately after stretching, and decreased subsequently. We found that although stretch stimuli caused cultured myoblasts to transiently express MHC-2b which is an isoform with the strongest contraction force (1), continued stimulation subsequently reduced MHC- $2 b$.

Compared to the control group, the stretch group expressed low levels of MHC-2d. An in vivo study has suggested that, in response to muscle functional changes, MHC-2d is converted to MHC-2b with a strong contraction force, or to MHC-2a with a weak but sustained contraction force (15). Calcineurin activation has been reported to induce muscular hypertrophy (16). Calcineurin activity is stimulated by frequent activation of motor nerves, which in turn, facilitates genetic expression of slow-twitch fibers. On the other hand, suppression of calcineurin activity converts muscle fibers to fast-twitch fibers (4). In this study, low levels of MHC-2d and abundant MHC-2a were present in the stretch group. MHC-2a is more resistant against fatigue when compared to MHC- $2 b$, and is superior in oxidative metabolism (10). It is generally accepted that MHC-2b is more 
adept at anaerobic exercise, while MHC-2a is more adept at aerobic exercise. We speculate that, therefore, in response to continued stimuli to myoblasts, MHC-2d acquired the properties of MHC-2a suitable for aerobic exercise, or underwent conversion to MHC-2a. Different results may be provided when they change different stretching intensities and frequencies on muscles. Several studies have previously documented that the higher the frequency of electric stimulation were applied, the greater the expression of slow-twitch isoforms appeared, while lower frequencies of electric stimulation result in greater expression of fast-twitch isoforms $(12,18)$. In addition, MHC-1 is not expressed the soleus muscle of juvenile rats, however it was expressed when mild electrical stimulation was continuously applied (11). In other words, changes in the MHC isoform composition appear to be dependent on stimulation intensity and frequency.

In the control group the fastest muscle isoform MHC-2b showed low levels of change in any stage. Among the fast muscle types, the slowest muscle isoform MHC-2a increased transiently, but decreased thereafter. In contrast, the intermediate type MHC-2d increased slightly in a time-dependent manner. It has been suggested that MHC-2d is reversibly converted to MHC-2b or MHC-2a (15). Therefore MHC-2d increased presumably in response to environmental changes in the control group. MHC-2a in the stretch group was significantly higher than that in the control group, while MHC-2d in the stretch group was markedly lower than that in the control group. These results suggest that myoblasts tend to change into the more adapted muscle fibers on application of stretch stimuli.

Our results showed that, when skeletal muscle myoblasts were mechanically stretched, cell growth was facilitated, and the number of cells reached a plateau earlier when compared to the control group. The number of myoblasts in the stretch group was also greater than that for the control group. As far as to factors affecting the composition of MHC isoforms, mRNA expression in MHC-2b (fast-twitch isoform with the fastest contraction speed) increased early, but continuous stimulation decreased expression with passage of time. On the other hand, mRNA expression in MHC-2a (fast-twitch isoform with the slowest contraction speed) increased with time and was markedly greater when compared to the control group. In other words, although the resulting muscle fibers were of a fast-twitch type, they had properties associated with slow-twitch fibers. Furthermore, mRNA expression in intermediate
MHC-2d hardly increased in the stretch group. Therefore, when external stimuli such as stretching are applied, muscle fibers adapt quickly to environmental changes, thus clarifying the relationship between mechanical stimuli and muscle function changes at the mRNA level.

\section{Acknowledgements}

This study was supported by Oral Health Science Center Grant 5A10 from Tokyo Dental College and by grants-in-aid for scientific research (14704046: S.A.) from the Ministry of Education, Culture, Sports, Science and Technology, Japan. The authors wish to thank Professor Shimono, Dept. of Pathology and Professor Inoue, Dept. of Clinical Pathophysiology in Tokyo Dental College for providing the experimental instruments in this study.

\section{REFERENCES}

1. Bottinelli R, Schiaffino S and Reggiani C (1991) Force-velocity relations and myosin heavy chain isoform compositions of skinned fibers from rat skeletal muscle. $J$ PhysiolLondon 437, 655-672.

2. Brueckner JK, Itkis O and Porter JD (1996) Spatial and temporal patterns of myosin heavy chain expression in developing rat extraocular muscle. J Muscle Res Cell Motil 17, $297-$ 312.

3. Buck RC (1980) Reorientation response of cells to repeated stretch and recoil of the substratum. Exp Cell Res 127, 470 474.

4. Chin ER, Olson EN, Richardson JA, Yang Q, Humphries C, Shelton JM, Wu H, Zhu W, Bassel-Duby R and Williams RS (1998) A calcineurin-dependent transcriptional pathway controls skeletal muscle fiber type. Genes Dev 12, 2499-2509.

5. Dartsch PC and Hammerle H (1986) Orientation response of arterial smooth muscle cells to mechanical stimulation. Eur $J$ Cell Biol 41, 339-346.

6. Gojo K, Abe S and Ide Y (2002) Characteristics of myofibers in the masseter muscle of mice during postnatal growth. Anat Histol Embryol 31, 105-112.

7. Goto S, Miyazaki K, Funabiki T and Yasumitsu H (1999) Serum-free culture conditions for analysis of secretory proteinases during myogenic differentiation of mouse $\mathrm{C} 2 \mathrm{C} 12$ myoblasts. Anal Biochem 272, 135-142.

8. Guharay F and Sachs F (1984) Stretch-activated single ion channel currents in tissue-cultured embryonic chick skeletal muscle. J Physiol-London 55, 685-701.

9. Kim S-G, Akaike T, Sasagawa T, Atomi Y and Kurosawa $\mathrm{H}$ (2002) Gene expression of type I and type III collagen by mechanical stretch in anterior cruciate ligament cells. Cell Struct Funct 27, 139-144.

10. Larsson L, Edstrom L, Lindegren B, Gorza L and Schiaffino S (1991) MHC composition and enzymehistochemical and physiological properties of a novel fast-twitch motor unit type. Am J Physiol 261, 93-101.

11. Miller JB (1990) Myogenic program of mouse muscle cell line: Expression of myosin heavy chain isoform, MyoD 1, and Myogenin. J Cell Biol 111, 1149-1159. 
12. Naumann K and Pette D (1994) Effects of chronic stimulation with different impulse patterns on the expression of myosin isoforms in rat myotube cultures. Differentiation 55, 203-211.

13. Nonaka I, Takagi A, Ishiura S, Nakase H and Sugita H (1983) Pathophysiology of muscle fiber necrosis induced by bupivacaine hydrochloride (Marcaine). Acta Neuropathol (Berl) 60, 167-174.

14. Pette D and Starton RS (1990) Cellular and molecular diversities of mammalian skeletal muscle fibers. Rev Physiol Bioch $P$ 116, 1-76.

15. Sartorius CA, Lu BD, Acakpo-Satchivi L, Jacobsen RP, Byrnes WC and Leinwand LA (1998) Myosin heavy chains 2a and $2 \mathrm{~d}$ are functionally distinct in the mouse. J Cell Biol 141, 943-953.

16. Semsarian C, Wu MJ, Ju YK, Marciniec T, Yeoh T, Allen DG, Harvey RP and Graham RM (1999) Skeletal muscle hypertrophy is mediated by a $\mathrm{Ca}^{2+}$-dependent calcineurin signaling pathway. Nature 400, 576-581.

17. Shida T, Abe S, Sakiyama K, Agematsu S, Mitarashi S, Ta- matsu Y and Ide Y (2005) Superficial and deep layer muscle fibre properties of the mouse masseter before and after weaning. Arch Oral Biol 50, 65-71.

18. Sreter FA, Gergely J, Salmons S and Romanul F (1973) Synthesis by fast muscle in response to longterm stimulation. Nature New Biol 241, 17-18.

19. Usami A, Abe S and Ide Y (2003) Myosin heavy chain isoforms of the murine masseter muscle during pre and post-natal development. Anat Histol Embryol 32, 244-248.

20. Vandenburgh HH and Kaufman S (1982) Coupling of voltage-sensitive sodium channel activity to stretch-induced amino acid transport in skeletal muscle in vitro. $J$ Biol Chem 257, 13448-13454.

21. Vandenburgh HH (1988) A computerized mechanical cell stimulator for tissue culture: effects on skeletal muscle organogenesis. In Vitro Cell Dev Biol 24, 609-619.

22. Yaffe D and Saxel O (1977) Serial passaging and differentiation of myogenic cells isolated from dystrophic mouse muscle. Nature 270, 725-727. 